\title{
TANGGUNG JAWAB SOSIAL PERUSAHAAN (CSR) PERBANKAN
}

(ANALISIS HUKUM PELAKSANAAN CSR PADA BANK AMAN SYARI'AH, LAMPUNG TIMUR, INDONESIA)

\author{
Desi Wahyuni \\ Universitas Islam Negeri Sunan Kalijaga Yogyakarta \\ E-mail : desiwahyuni152@gmail.com
}

\begin{abstract}
CSR is no longer intended to pay social debt, but it has become an absolute responsibility that must be carried out by the company in maintaining and establishing its social communication towards the community and the surrounding environment, and this has been ruled by Indonesian National Legislation, specially corporate legislation. This study aims to provide input for Islamic Financial Institutions (LKS) especially Islamic Banks to better implement Social Responsibility (CSR) for the interests of stakeholders so that it can be useful for Sharia Bank policy makers as financial institutions that can prosper the community. This type of research is a field research, which uses several methods, namely the method of interviewing and documentation in data collection. Conclusions from this study that the implementation of CSR programs can prosper the surrounding community in accordance with Islamic business ethics.
\end{abstract}

Keyword: Social Resposiblity, Corporation, Islamic Financial Institution.

\section{Abstrak}

CSR saat ini tidak lagi ditujukan untuk membayar hutang sosial, melainkan sudah menjadi sebuah tanggung jawab yang mutlak yang harus dilakukan oleh perusahaan dalam menjaga dan menjalin komunikasi sosialnya terhadap masyarakat dan lingkungan sekitar. Perihal CSR ini diatur dalam peraturan perundang-undangan nasional, Khususnya undang-undang yang membahas tentang korporasi, termasuk korporasi perbankan. Penelitian ini bertujuan untuk untuk memberikan masukan bagi Lembaga Keuangan Syariah (LKS) khususnya Bank Syariah untuk lebih baik dalam menerapkan Tanggung Jawab Sosial (CSR) bagi kepentingan stakeholder sehingga dapat bermanfaat terhadap pengambil kebijakan Bank Syariah sebagai lembaga keuangan yang dapat 
mensejahterakan masyarakat. Jenis penelitian ini merupakan penelitian lapangan, yang menggunakan beberapa metode yaitu metode wawancara dan dokumentasi dalam pengumpulan data.Kesimpulan dari penelitian ini bahwa pelaksanaan program CSR tersebut dapat mensejahterakan mayarakat sekitar sesuai dengan etika bisnis Islam.

Kata Kunci : Tanggung Jawab Sosial, korporasi, lembaga keuangan syari'ah.

\section{Pendahuluan}

Tanggung jawab sosial perusahaan (Corporate Social Responsibility) merupakan salah satu dari beberapa tanggung jawab perusahaan kepada pemangku kepentingan (stakeholders). Pemangku kepentingan dalam hal ini adalah orang atau kelompok yang dapat mempengaruhi atau dipengaruhi oleh berbagai keputusan, kebijakan, maupun operasional perusahaan. ${ }^{1}$

Bagi umat Islam kegiatan bisnis, termasuk bisnis perbankan, tidak boleh keluar dari koridor dan aturan Syari'at Islam. Karenanya dalam berbisnis perlu pembicaraan yang transparan antara semua pihak, baik pengusaha, pemerintah, masyarakat maupun pihak lain agar tidak hanya satu pihak mendapatkan apa yang mereka inginkan sementara pihak yang lain tidak. Dengan kata lain dalam perspektif hukum bila ada salah satu pihak yang tidak mengetahui dan atau tidak paham dengan apa yang menjadi kesepakatan maka kesepakatan itu dapa batal demi hukum dan tentu saja melanggar etika dan moral dalam bisnis. Kareni itu kesadaran akan hukum dan etika moral dalam bisnis menjadi sangat penting bagi para pelaku bisnis, ${ }^{2}$ dengan demikian akan tercipta bisnis yang menjamin adanya kepedulian antara satu pihak dan pihak lain tidak dan yang tidak merugikan siapapun baik secara hukum maupun perekonomian.

\footnotetext{
${ }^{1}$ Solihin Ismail, (Jakarta: Salemba Empat, 2009), HIm..4.

${ }^{2}$ Agus Arijanto, (Jakarta: PT Raja Grafindo Persada, 2012), HIm.3.
} 
Islam mengajarkan keteraturan dan kepatutan karena itu penting aspek syara'/hukum dan akhlaq/etika moral menjadi salah satu acuan utama dalam mu'amalah ma'a al-nnas. Adanya hukum dan etika bisnis baik dalam Hukum Bisnis Islam maupun konvensional bertujuan untuk mengajarkan manusia agar saling bekerjasama, tolong menolong, dan menjauhkan diri dari sikap dengki dan dendam serta hal yang tidak termasuk dalam prinsip syariah. Etika bisnis dalam islam juga berfungsi sebagai controlling (pengatur) terhadap aktivitas ekonomi dan bisnis, karena secara filosofi etika mendasarkan diri pada nalar ilmu dan agama untuk menilai. ${ }^{3}$

CSR merupakan pengambilan keputusan perusahaan yang dikaitkan dengan nilai-nilai etika, dengan memenuhi kaidah-kaidah ketaatan pada hukum, menjunjung tinggi harkat martabat manusia, masyarakat, dan lingkungan. ${ }^{4}$ Hal ini yang menjadi perhatian terbesar dari peran perusahaan dalam masyarakat yaitu meningkatkan kepekaan dan kepedulian terhadap lingkungan dan masalah etika.

Bank Aman Syariah Lampung Timur merupakan salah satu bank yang menerapkan tanggung jawab sosial (CSR) ini. Bank Aman dituntut untuk dapat memanfaatkan sumber daya ekonomi dalam kegiatan operasional untuk menyediakan dan memberikan kontribusi kepada para pemegang kepentingan baik dari pihak internal dan eksternal pada bank tersebut. Pelaksanaan CSR pada Bank Aman Syariah ditujukan bukan hanya untuk memenuhi aturan dan regulasi DPS saja, melainkan menjadi salah satu bentuk kepedulian sosial lembaga keuangan untuk dapat ikut mensejahterakan masyarakat, namun tetap harus sesuai dengan apa yg

\footnotetext{
${ }^{3}$ Firtia Afrilia dkk, (Bandung, Posising Penelitian Spesia), Gelombang tahun akademik -2015 2014.

${ }^{4}$ Erni R. Ernawan, (Bandung : Alfabeta, 2011), HIm.160.
} 
telah diatur dalam syara' maupun dalam etika bisnis Islam yang berlandaskan Al-Qur'an dan As-Sunnah. ${ }^{5}$

Praktik Pengelolaan dana CSR pada Bank Aman Syari'ah masih disatukan dengan pengelolaan dana Zakat, Infaq dan Shadaqah (ZIS). Dana CSR diambil dari keuntungan (profit) yang diperoleh yang telah disatukkan, selanjutnya akan disalurkan kepada mereka yang dianggap berhak, dengan memperhatikan 8 ashnaf penerima ZIS terlebih dahulu, lalu sisa dana tersebut disalurkan untuk kegiatan-kegiatan sosial di daerah beroperasinya Bank Aman Syariah. ${ }^{6}$

Dari hasil survey yang telah dilakukan didapatkan gambaran bahwa pengelolaan CSR di Bank Aman Syariah masih menjadi satu dan belum dipisahkan dari dengan dana Zakat Infaq Shadaqah, dan kegiatan tindak lanjut dari penyaluran dana $C S R$ belum dilakukan karena alasan efisiensi waktu. Berda-sarkan hal tersebut maka peneliti tertarik untuk melakukan penelitian praktik dan pelaksanaan Tanggung Jawab Sosial (CSR) Perbankan Syariah Menurut hukum Bisnis Islam pada Bank Aman Syariah Sekampung Lampung Timur.

\section{Pembahasan}

\section{Kriteria Corporate Social Responsibility (CSR) Lembaga Keuangan Syariah}

Selama ini, terdapat anggapan yang keliru bahwa pelaksanaan CSR hanya diperuntukkan bagi perusahaan besar, padahal tidak hanya perusahaan besar yang dapat memberikan dampak negatif terhadap masyarakat dan lingkungan melainkan perusahaan kecil dan

5 Bapak Sugianto, Direktur Bank Aman Syariah (Pengelola CSR), wawancara pada 3 Oktober 2017 pukul 09.30WIB

${ }^{6}$ Bapak Sugianto, Direktur Bank Aman Syariah (Pengelola CSR), wawancara pada 16 Oktober 2017 pukul 09.00 WIB 
menenggahpun bisa memberikan dampak negatif terhadap masyarakat dan lingkungan sekitarnya. ${ }^{7}$

Kriteria CSR mempunyai hubungan yang erat dengan konsep hubungan tanggung jawab sosial yang di perankan oleh manusia sebagai khalifah di bumi. Tiga hubungan tanggung jawab sosial tersebut yaitu hubungan tanggung jawab manusia dengan Allah SWT, hubungan tanggung jawab manusia dengan sesama manusia, dan hubungan manusia dengan alam sekitar.. ${ }^{8}$ Dari hubungan tersebut telah dibentuk enam kriteria CSR sebagai instrumen untuk mengukur pelaksanaan CSR di LKS, ia melibatkan berbagai stakeholder di LKS. ${ }^{9}$ Enam kriteria CSR di LKS tersebut yaitu:

\section{Kepatuhan Syariah}

Fungsi kepatuhan merupakan tindakan dan langkah yang bersifat ex-ante (preventif), untuk memastikan kebijakan, ketentuan, sistem dan prosedur, serta kegiatan usaha yang dilakukan oleh Bank Islam sesuai dengan ketentuan Bank Indonesia, fatwa DSN dan peraturan perundang-undangan yang berlaku. Hal ini dilakukan untuk mengontrol operasional perbankan syariah serta menjadikan bank syariah agar tidak keluar dari koridornya, disiplin dan langkah untuk meminimalisir resiko perbankan. ${ }^{10}$ Untuk mengukur kriteria kepatuhan syariah dalam kaitannya dengan praktik CSR di LKS, maka ada lima item yang telah jelas memiliki hubungan erat untuk dijadikan sebagai instrumen, yaitu;

\footnotetext{
${ }^{7}$ Solihin Ismail, HIm.161-162.

${ }^{8}$ Muhammad Yasir Yusuf, (Jakarta: Kencana, 2017), HIm.75.

${ }^{9}$ Muhammad Yasir Yusuf, HIm.75.

${ }^{10}$ Budi Sukardi, Akademika, (Metro: STAIN Jurai Siwo Metro), Vol 17,
} No 2 (2012): HIm.3. 
a) Instrumen-instrumen LKS sesuai dengan ketentuan syariah;

b) Pembiayaan LKS diberikan sesuai dengan ketentuan syariah;

c) Tempat dan produk halal;

d) Menghindari keuntungan yang didapat secara tidak halal;

e) Pemilihan stakeholder LKS yang sesuai dengan ketentuan syariah; ${ }^{11}$

2. Keadilan dan Kesetaraan

Kegiatan operasional di LKS sebagai institusi keuangan Islam harus mengedepankan nilai-nilai keadilan dalam memberikan pelayanan kepada stakeholder. Komitmen sosial bank syariah itu sendiri dilandasi oleh prinsip persaudaraan (brotherhood) dan keadilan yang menjunjung tinggi nilai-nilai kemanusiaan sebagai tujuan utama Islam. ${ }^{12}$ Untuk mengukur kriteria kesamaan dalam operasional LKS, maka ada empat item yang bisa dijadikan sebagai instrumen tersebut, yaitu:

a) Adanya nilai-nilai persaudaraan;

b) Pelayanan yang berkualitas;

c) Tidak adanya diskriminasi;

d) Mempunyai kesempatan yang sama. ${ }^{13}$

3. Bertanggung Jawab dalam Bekerja

Penerapan kriteria bertanggung jawab dalam bekerja akan tercermin daam nilai-nilai yang secara umum dapat dibagi dalam dua perspektif yaitu mikro dan makro.

${ }^{11}$ Budi Sukardi, HIm.3.

12 Siti Amaroh, Jurnal Ekonomi Islam, (Semarang: Fakultas Ekonomi dan Bisnis Islam UIN Walisongo), Vol 5, No 2 (2014): HIm.89.

${ }^{13}$ Muhammad Yasir Yusuf, HIm.78. 
Bertanggung jawab dalam perspektif mikro menghendaki bahwa semua dana yang diperoleh dalam sistem LKS dikelola dengan integritas tinggi dan sangat berhati-hati dengan mencerminkan sifat-sifat siddiq (benar), tabligh (menyampaikan), amanah, dan fathanah (cerdas). ${ }^{14}$ Sedangkan bertanggung jawab dalam perspektif makro berarti LKS harus memberikan kesejahteraan bagi masyarakat dengan memfungsikan zakat untuk mempengaruhi perilaku masyarakat untuk lebih menyukai investasi diandingkan menyimpan harta, prinsip pelarangan riba dengan menganjurkan pembiayaan bersifat bagi hasil, pelarangan judi atau maisir tercermin dengan kegiatan LKS yang melarang investasi bukan dari sektor riil, dan mengutamakan ketulusan dalam melakukan transaksi dan kegiatan operasional lainnya serta menghindari ketidakjelasan. $^{15}$

Dari penjelasan diatas maka item yang diindentifikasi untuk mengukur kriteris bertanggung jawan dalam bekerja yaitu;

a) Amanah

b) Bekerja sesuai dengan kewajiban dan bertanggung jawab

c) Ikhlas

d) Optimal dalam penggunaan waktu dan kepakaran

e) Mengurangi image buruk dalam investasi

f) Integrias dalam bekerja

g) Berlaku adil dalam persaingan

h) Akuntabilitas. ${ }^{16}$

\footnotetext{
${ }^{14}$ Abdul Azis, (Bandung: Alfabeta, 2013), HIm.212.

${ }_{15}$ Muhammad Yasir Yusuf, HIm. 80.

${ }^{16}$ Muhammad Yasir Yusuf, HIm.81.
} 
4. Jaminan Kesejahteraan

Tanggung jawab sosial merupakan kepedulian perusahaan untuk menjalankan operasi terhadap masyarakat, dan kelompok-kelompok yang beroperasi di bawah ruang lingkupnya. ${ }^{17}$ Untuk mengukur kriteria jaminan kesejahteraan CSR di LKS maka dirumuskan item sebagai instrumen, yaitu;

a) Tempat bekerja yang aman dan nyaman.

b) Kebebasan berkehendak.

c) Upah yang sesuai.

d) Pelatihan dan pendidikan.

e) Jam kerja yang manusiawi.

f) Pembagian keuntungan dan kerugian yang adil. ${ }^{18}$

5. Jaminan Kelestarian Alam

Setiap tindakan LKS dalam mewujudkan CSR bagi kelestarian alam dilakukan dengan tiga prinsip utama. Pertama, menghargai keseimbangan sunnatullah dalam penciptaan alam semesta. Kedua, tidak merusak dan membahayakan. Ketiga, menjaga kelestarian lingkungan dalam operasionalnya. ${ }^{19}$

Oleh sebab itu, ada empat item yang dapat dibangun untuk mengukur kriteria jaminan kelestarian alam terlaksana dengan baik dalam operasional LKS. Ssebagai salah satu bentuk tanggung jawab LKS terhadap alam, agar tetap lestari bagi generasi yang akan datang, yaitu:

\footnotetext{
${ }^{17}$ Totok Mardikanto, (Bandung: Afabeta, 2014), HIm.148.

${ }^{18}$ Muhammad Yasir Yusuf, HIm..83.

${ }^{19}$ Muhammad Yasir Yusuf, HIm.84.
} 
a) Memastikan realisasi program LKS tidak merusak alam sekitar.

b) Ikut berperan aktif dalam menjaga alam sekitar.

c) Medidik pekerja menjaga dan merawat alam sekitar (seperti menggunakan bahan-bahan yang dapat didaur ulang).

d) Menggunakan bahan-bahan ramah lingkungan dalam memenuhi keperluan LKS.

6. Bantuan Kebajikan atau sosial

Lembaga Keuangan Syariah sebagai suatu lembaga dan bahkan keseluruhan sisten ekonomi syariah, bertujuan untuk mewujudkan kesejahteraan dan keadilan dalam masyarakat sebagaimana dikehendaki oleh syariah itu sendiri. Oleh sebab itu LKS bukan sekedar institusi yang melepas diri dari perintah norma-norma dalam memenuhi kewajibannya pada persoalan CSR. Akan tetapi, lebih dari itu, LKS adalah suatu sistem yang bertujuan untuk menyumbang kebaikan dalam memenuhi visi sosio-ekonomi dan mewujudkan masyarakat yang adil dan sejahtera. Keberadaan LKS juga ikut membantu meringankan bebanbeban masyarakat yang kurang mampu, terutama persoalan ekonomi.

Oleh karena itu, perlu diteapkan kriteria sebuah CSR memenuhi aspek-aspek tertentu sehingga memenuhi kiteria untuk disebut sebagai CSR yang bercirikan bantuan sosial, terdapat lima kriteria yang harus dipenuhi LKS, yaitu;

a) Pemilihan lembaga yang dapat menunjag visi LKS memenuhi misi CSR.

b) Ikut meringankan masalah sosial (seperti bantuan sosial). 
c) Membantu program kemasyarakatan (seperti membantu dana pendidikan, dan meringankan beban kehidupan anak yatim), dan lain-lain.

d) Menjalankan program CSR dengan tidak hanya berorientasi pada keuntungan semata-mata.

e) Pemberdayaan masyarakat melalui produk-produk LKS (seperti qard, pembiayaan mikro ekonomi untuk usaha kecil dan menengah (UKM). ${ }^{20}$

Dari penjelasan diatas dapat dipahami, bahwa pelaksanaan CSR di LKS dengan enam kriteris sebagai instrumen yang digali dari Alqur'an dan As-sunnah dapat membantu mengharmonisasikan semua kepentingan para pihak yang terlibat di LKS seperti pemilik, pemegang saham, karyawan, pengguna dan masyarakat. Pelaksanaan CSR di LKS bukan hanya sekedar menggunakan kewajiban yang telah diperintahkan oleh undang-undang, akan tetapi pelaksanaan CSR di LKS adalah suatu bentuk pertanggungjawaban kepada Allah SWT, manusia, dan alam sekitar. Pelaksanaan CSR di LKS benar-benar diharapkan mampu memberikan dampak positif bagi menyelesaikan dan meringankan maslaah sosial, baik yang terjadi dalam institusi LKS maupun masyarakat, terutama untuk memberdayakan ekonomi masyarakat lemah.

\section{Tujuan Dan Manfaat Corporate Social Responsibility (CSR)}

Implementasi corporate social responsibility (CSR) memiliki tujuan dan manfaat yang akan diterima bagi perusahaan sebagai berikut:

a. Mempertahankan dan merenungkan reputasi serta citra perusahaan mereka.

b. Mendapatkan lisensi untuk beroprasi secara sosial.

c. Mereduksi risiko bisnis perusahaan.

\footnotetext{
${ }^{20}$ Muhammad Yasir Yusuf, HIm. 86.
} 
d. Melebarkan aksesoris berdaya bagi operasional usaha.

e. Membuka peluang pasar yang lebih luas.

f. Mereduksi biaya misalnya terkait dampak pembuangan limbah.

g. Memperbaiki hubungan dengan stakeholder.

h. Memperbaiki hubungan dengan regulator. ${ }^{21}$

i. Meningkatkan semangat dan produktivitas karyawan. ${ }^{22}$

j. Peluang mendapatkan penghargaan. ${ }^{23}$

Mencermati pendapat diatas, salah satu tujuan CSR adalah membangun reputasi dan citra positif perusahaan dalam pandangan masyarakat. Program CSR merupakan investasi bagi perusahaan demi pertumbuhan dan keberlanjutan perusahaan dan bukan lagi dilihat sebagai sarana biaya melainkan sebgai sarana meraih keuntungan.

\section{Etika Bisnis Dalam Hukum Islam}

Etika Bisnis Islam telah diajarkan Nabi SAW., saat menjalankan perdagangan. Karakteristik Nabi SAW., sebagai pedagang adalah selain dedikasi keuletannya juga me-miliki sifat; shidiq, fathanah, amanah, dan tabligh. Ciri-ciri tersebut masih di tambah is-tiqamah. Shidiq berarti mempunyai kejujuran dan selalu melandasi ucapan, keyakinan dan amal pebuatan atas dasar nilai-nilai yang diajarkan Islam. Istiqamah atau konsisten dalam iman dan nilai-nilai kebaikan, meski menghadapi godaan dan tantangan. Istiqomah dalam kebaikan ini ditampilkan dalam keteguhan, kesabaran serta keuletan sehingga me-nghasilkan sesuatu yang optimal. Fathanah berarti mengerti, memahami, dan meng-hayati secara mendalam segala yang menjadi tugas dan kewajibannya. Sifat ini akan me-nimbulkan kreatifitas dan kemampuan melakukan berbagai

\footnotetext{
${ }^{21}$ Hendri Budi Untung, (Jakarta: Sinar Grafika, 2009), HIm.6.

${ }^{22}$ Firsan Nova, (Jakarta: media bangsa, 2012), HIm.321-322.

${ }^{23}$ Irham fahmi, (Bandung: Alfabeta, 2013), HIm..83.
} 
macam inovasi yang berman-faat. Amanah, tanggung jawab dalam melaksanakan setiap tugas dan kewajiban. Amanah ditampilkan dalam keterbukaan, kejujuran, pelayanan yang optimal, dan ihsan (kebajikan) dalam segala hal. Tabligh, mengajak sekaligus memberikan contoh kepada pihak lain untuk melaksanakan ketentuan-ketentuan ajaran Islam dalam kehidupan sehari-hari. ${ }^{\mathbf{2 4}}$

Etika bisnis secara umum menurut Suarny Amran sebagaimana yang dikutip oleh Abdul Aziz harus berlandaskan prinsip-prinsip sebagai berikut:

a. Prinsip otonomi; yaitu kemampuan untuk mengambil keputusan dan bertidak berdasarkan keselarasan tentang apa yang baik untuk dilakukan dan bertanggung jawab secara moral atas keputusan yang diambil.

b. Prinsip kejujuran; dalam hal ini kejujuran adalah adalah merupakan kunci keberhasilan suatu bisnis, kejujuran dalam pelaksanaan kontrol terhadap konsumen, dalam hubungan kerja, dan sebagainya.

c. Prinsip keadilan; bahwa setiap orang dalam berbisnis diperlakukaan sesuai dengan haknya masing-masing dan tidak ada yang boleh dirugikan.

d. Prinsip saling menguntungkan; juga dalam bisnis yang kompetitif.

e. Prinsip Integrasi moral; ini merupakan dasar dalam berbisnis, harus menjaga nama baik perusahaan tetap dipercaya dan merupakan perusahaan terbaik. $^{25}$

Berdasarkan sifat dan prinsip tersebut, dalam konteks corporate sosial responsibility (CSR) dalam etika bisnis Islam, para pelaku usaha 
atau pihak perusahaan dituntut tidak bersikap kontradiksi secara sengaja antara ucapan dan perbuatan dalam bisnisnya. Mereka dituntut tepat janji, tepat waktu, mengakui kelemahan dan kekurangan (tidak ditutup-tutupi), selalu memperbaiki kualitas barang dan jasa secara berkesinambungan serta tidak boleh menipu dan berbohong. Pelaku usaha atau pihak perusahaan harus memiliki amanah dengan menampilkan sikap keterbukaan, kejujuran, pelayanan yang optimal, dan ihsan (berbuat baik) dalam segala hal, apalagi berhubungan dengan pelayanan masyarakat. ${ }^{26}$

\section{Penerapan Corporate Social Responsibility (CSR) Di Bank Aman Syariah}

Berdasarkan wawancara kepada pengelola CSR di Bank Aman Syariah yaitu Bapak Sugiyanto bahwa CSR di Bank Aman Syariah dijalankan atas dasar bentuk kepedulian dengan lingkungan sekitar, ingin meningkatkan ekonomi masyarakat kecil yang tidak mampu, dan agar keberadaan Bank dapat bermanfaat bagi masyarakat. ${ }^{27}$ Pengelolaan dana CSR pada Bank Aman Syariah masih dikelola menjadi satu dengan dana Zakat, Infaq dan Shadaqah (ZIS). Dana CSR yang diambil dari 2,5\% keuntungan (profit) kemudian dijadikan satu dengan dana ZIS. Setelah dana tersebut dikelola menjadi satu, selanjutnya akan disalurkan dengan memperhatikan 8 ashnaf penerima ZIS terlebih dahulu lalu sisa dana tersebut disalurkan untuk kegiatan-kegiatan sosial di daerah beroprasinya Bank Aman Syariah. ${ }^{28}$

Bank Aman Syariah mempunyai peraturan internal yang harus ditaati oleh pengelola CSR yaitu penyaluran dana CSR yang maksimal Rp 250.000 per-orang. Kemudian, dana CSR yang disalurkan sifatnya

\footnotetext{
${ }^{26}$ Firsan Nova, HIm.213.

${ }^{27}$ Bapak Sugianto, Direktur Bank Aman Syariah (Pengelola CSR), wawancara pada 27 Desember 2017 pukul 09.30WIB

28 Bapak Sugianto, Direktur Bank Aman Syariah (Pengelola CSR), wawancara pada 27 Desember 2017 pukul 09.30 WIB
} 
bisa proposional dengan melihat kondisi keuangan Bank Aman Syariah, dengan kisaran penyaluran dana pertahun mencapai Rp 35.000.000. ${ }^{29}$ Program CSR yang dijalankan oleh Bank Aman Syariah berupa penyaluran dana baik dana konsumtif maupun dana produktif. Penyaluran dana konsumtif pada Bank Aman Syariah hanya gencar dilakukan saat menjelang Ramadhan. Dana-dana CSR tersebut disalurkan sebagai dana sosial untuk Sekolah, Masjid, Yayasan, Pondok Pesantren, dan sumbangan desa dalam partisipasi acara yang diselenggarakan oleh Desa Sumber Gede lokasi Bank Aman Syariah beroprasi. Kemudian, penyaluran dana produktif yang dikelola dari dana CSR Bank Aman Syariah adalah usaha jamur tiram yang didirikan oleh pondok pesantren Miftahul Jannah dan usaha peternakan ayam yang didirikan oleh Pondok Pesantren As'ari. Namun, untuk tindak lanjut penyaluran dana produktif tidak dilakukan dikarenakan efisiensi waktu. ${ }^{30}$

Berdasarkan wawancara dengan Bapak Nurkholis selaku penerima dana CSR Bank Aman Syariah, bahwa program CSR yang disalurkan oleh bank Aman Syariah sangat membantu untuk mencukupi kebutuhan pangan pada saat bulan ramadhan dan musim gagal panen. ${ }^{31}$

Keberadaan Bank Aman Syariah di desa Sumber Gede sangat membantu kegiatan-kegiatan sosial yang dilakukan dilingkungan sekitarnya. Banyak kegiatan yang dilakukan oleh pemuda pemudi Desa dengan dana sumbangan Bank Aman Syariah. Sehingga dengan keberadaan Bank Aman Syariah tersebut Desa Sumbergede menjadi maju. Bank aman syariah sangar memperhatikan aspek sosial dan religius

${ }^{29}$ Bapak Toni Utomo, Direktur Utama Bank Aman Syariah (Pengelola CSR), wawancara pada 27 Desember 2017 pukul 10.00 WIB

${ }^{30}$ Bapak Sugianto, Direktur Bank Aman Syariah (Pengelola CSR), wawancara pada 27 Desember 2017 pukul 09.30 WIB

${ }^{31}$ Bapak Nurkholis, Penerima dana CSR (konsumtif), wawancara pada 27 Desember 2017 pukul 11.00 WIB 
seperti sumbangan untuk masjid, sumbangan untuk kegiatan HUT RI, Maulid Nabi, ulang tahun desa dan lain sebagainya. ${ }^{32}$

Bank Aman Syariah sangat memperhatikan lingkungan sekitar. Dengan adanya program CSR di Bank Aman Syariah mampu memberikan konstributsi untuk bertanggung jawab dalam kegiatan sosial yang diadakan oleh kelurahan Desa Sumber Gede tempat berdirinya Bank Aman Syariah dengan menyisihkan sebagian keuntungan dari omset yang diperoleh. Sehingga CSR di Bank aman Syariah sangat mengdepankan etika dalam berbisnis yang dapat diwujudkan dengan bentuk kepeduliannya. $^{33}$

Berbicara etika bisnis, Bank Aman Syariah merupakan salah satu Bank Syariah yang ada di Sekampung yang mampu menjadi sebuah lembaga keuangan yang memperhatikan lingkungan. Pelayanan dari Bank Aman Syariah terhadap masyarakat baik dari golongan menengah kebawah maupun menengah keatas tidak memiliki perbedaan. Semua pegawai Bank Aman Syariah terlihat sopan dan ramah-ramah lingkungan. ${ }^{34}$

Berdasarkan wawancara dengan pengelola dan penerima CSR, dapat dipaparkan bahwa penerapan CSR di Bank Aman syariah mampu mensejahterahkan masyarakat sekitar. Dengan kepeduliannya bank aman syariah terhadap lingkungan sekitar mampu menciptakan brand image dilingkungan sekitar sehingga mampu menciptakan kepercayaan masyarat untuk menggunakan jasa keuangan. Namun, dana CSR yang disalurkan belum efektif dimana kepengurusan CSR di bank aman

32 Bapak Prambodo, Penerima dana CSR (Kepala Desa Sumbergede Sekampung), wawancara pada 27 Desember 2017 pukul 11.00 WIB

${ }^{33}$ Bapak Sugianto, Direktur Bank Aman Syariah (Pengelola CSR), wawancara pada 27 Desember 2017 pukul 09.30 WIB

${ }^{34}$ Bapak Nurkholis, Penerima dana CSR (konsumtif), wawancara pada 27 Desember 2017 pukul 11.00 WIB 
syariah belum optimal sehingga tindak lanjut untuk dari penyaluran dana CSR tidak dilaksanakan.

\section{Analisis Tanggung Jawab Sosial (CSR) Di Bank Aman Syariah Menurut Etika Bisnis Islam.}

Peranan CSR di Bank Aman Syariah merupakan suatu bentuk kepedulian terhadap lingkungan sekitar. Konsep CSR juga harus dilandasi oleh argumentasi moral. ${ }^{35}$ Artinya CSR bukan saja upaya menunjukkan kepedulian sebuah organiasasi pada persoalan sosial dan lingkungan, namun juga dapat menjadi pendukung terwujudnya pembangunan yang berkesinambungan dengan menyeimbangan aspek ekonomi dan pembangunan sosial yang didukung dengan perlindungan lingkungan hidup.

Setelah peneliti melakukan penelitian di Bank Aman Syariah dapat mengetahui bahwa CSR di Bank Aman Syariah dilakukan atas dasar bentuk kepedulian dengan lingkungan sekitar, ingin meningkatkan ekonomi masyarakat kecil yang tidak mampu, dan agar keberadaan Bank dapat bermanfaat bagi masyarakat.

Kriteria CSR yang paling dominan yang dijalankan oleh Bank Aman Syariah adalah bantuan kebajikan atau sosial. Hal ini dapat dibutikan dengan indikator Bank Aman Syariah sebagai Lembaga keuangan syariah ikut membantu meringankan masalah sosial di Desa Sumbergede dan lingkungan sekitar, selanjutnya membantu program kemasyarakatan (seperti membantu dana pendidikan, dan meringankan beban kehidupan anak yatim). Hal tersebut dapat diperkuat bahwa pelaksanaan program CSR di Bank Aman Syariah sesuai dengan dimensi

35 T. Romi Marnelly, “Corporate Social Responsibility (CSR): Tinjauan Teori dan Praktek di Indonesia", Jurnal Aplikasi Bisnis, (Riau : Fakultas Ekonomi dan Bisnis Universitas Riau), Vol. 2 No. 2, (April 2012), h.52 
sosial yang dapat meberikan manfaat bagi masyarakat sekitar. Sehingga program CSR di Bank Aman Syariah menjadi sebuah transfer kekayaan dari si kaya ke si miskin yang dikelola dan diadministrasikan melalui kegiatan amal yaitu bantuan kebajikan atau sosial yang dapat di perbaiki kinerjanya secara kontinyu. Karena sifatnya bantuan kebajikan atau sosial, maka tindak lanjut yang dilakukan Bank Aman Syariah belum dilakukan secara optimal untuk memberdayakan masyarakat sekitar. Sehingga dana CSR yang diterima oleh masyarakat sifatnya lebih dominan menjadi dana yang konsumtif, berbeda dengan dana ZIS yang sifatnya konsumtif hanya habis digunakan sekali pakai.

Bank Aman Syariah seharusnya wajib memberikan sebuah pendampingan (edukasi) mengenai perbankan syariah terkhusus pemberian materi terkait permodalan, jasa-jasa perbankan, dan investasi kepada penerima CSR. Kegiatan tersebut dilakukan dengan sasaran agar dapat memberdayakan masyarakat sekitar, namun untuk kegiatan tindak lanjut dari penyaluran dana tersebut tidak dilakukan oleh bank Aman Syariah dengan alasan efisiensi waktu yang terbatas.

Berdasarkan etika bisnis Islam program CSR yang dijalankan oleh Bank Aman Syariah telah sesuai sifat-sifat yang telah dicontohkan Rasulullah SAW yaitu sidiq, amanah, fathanah, dan tabligh. Hal ini diperkuat dengan indikator bahwa Bank Aman Syariah tidak merugikan pihak manapun baik dari pelaku usaha maupun konsumen karena usaha yang dijalankan memiliki sifat keterbukaan, kejujuran, menumbuhkan hubungan kemanusiaan yang solid dan kuat, pelayanan yang optimal, dan ihsan (berbuat baik) dalam segala hal yang berhubungan dengan pelayanan masyarakat dan memiliki tanggung jawab untuk mengamalkan kewajiban-kewajibannya seperti program CSR.

Hal tersebut sesuai dengan Prinsip Integrasi moral dalam Etika Bisnis Islam sehingga program CSR di Bank Aman Syariah menjadi 
sebuah Lembaga Keuangan Syariah yang dapat dipercaya dalam menjalan kegiatan operasionalnya. Oleh karena itu, pelaksanaan CSR di Bank Aman Syariah bukan hanya sekedar menggunakan kewajiban yang telah diperintahkan oleh undang-undang, akan tetapi pelaksanaan CSR di Bank Aman Syariah adalah suatu bentuk pertanggungjawaban kepada Allah SWT.

Berdasarkan penjelasan diatas dapat dipaparkan bahwa Bank Aman Syariah telah menerapkan berbagai bentuk pertanggung jawaban sosial perusahaan (CSR) kepada sesama manusia tanpa dibatasi oleh waktu, apa bentuknya bisa materiil maupun non materiil, besarnya jumlah, dan kepada siapa pertanggung jawaban itu diberikan asalkan semua didasarkan kepada keiklasan dan didasarkan pada syari'at.

\section{Kesimpulan}

Pelaksanaan program CSR tersebut dapat mensejahterakan mayarakat sekitar. Hal tersebut dibuktikan dengan adanya beberapa dana CRS yang dapat mensejahterakan masyarakat seperti ikut berperan dalam pembangunan sarana ibadah, panti asuhan, pondok pesantren, sekolahan, sumbangan ulang tahun desa, dan sumbangan hari raya idul adha. Namun pelaksanaan program CSR di Bank Aman Syariah belum efektif. Hal ini dapat dibuktikan dengan indikator kepe-ngurusan CSR di bank aman syariah belum optimal dan pengelolaan dana CSR yang masih dikelola menjadi satu dengan dana Zakat sehingga tindak lanjut dari penyaluran dana CSR tidak dilaksanakan dan kebermanfaatan program CSR di Bank Aman Syariah belum maksimal untuk memberdayakan masyarakat sekitar.

Kemudian, pelaksanaan CSR di Bank Aman Syariah dapat disimpulkan sudah sesuai dengan Etika Bisnis Islam. Hal tersebut sesuai dengan Prinsip Integrasi moral .Oleh karena itu, pelaksanaan CSR di 
Bank Aman Syariah bukan hanya sekedar menggunakan kewajiban yang telah diperintahkan oleh undang-undang, akan tetapi pelaksanaan CSR di Bank Aman Syariah adalah suatu bentuk pertanggungjawaban kepada Allah SWT, lingkungan, dan sesama manusia.

\section{DAFTAR PUSTAKA}

Abdul Azis, Etika Bisnis Perspektif Islam: Implementasi Etika Islami untuk Dunia Usaha, Bandung: Alfabeta, 2013.

Agus Arijanto, Etika Bisnis bagi Pelaku Bisnis, Jakarta: PT Raja Grafindo Persada, 2012.

Budi Sukardi, "Kepatuhan Syariah (Shariah Compliance) Dan Inovasi Produk Bank Syariah Di Indonesia", Akademika, (Metro: STAIN Jurai Siwo Metro), Vol 17, No 2 (2012).

Erni R. Ernawan, Business Ethics-Etika Bisnis, Bandung : Alfabeta, 2011.

Firsan Nova, Republic Relation,Jakarta:media bangsa,2012.

Firtia Afrilia dkk, "Pengaruh Etika Bisnis Islam dalam terhadap Operasional Perbankan Syariah", dalam Akuntansi , (Bandung, Posising Penelitian Spesia), Gelombang 1 tahun akademik 20142015.

Hendri Budi Untung, Corporate Social Responsibility, Jakarta: Sinar Grafika, 2009.

Irham fahmi, Etika Bisnis Teori Kasus Dan Solusi, Bandung: Alfabeta, 2013.

Muhammad Yasir Yusuf, Islamic Corporate Social responsibility (I-CSR) Pada Lembaga Keuangan Syariah (LKS) Teori dan Praktik, Jakarta: Kencana, 2017.

Siti Amaroh, "Prinsip Keadilan Sosial Dan Altruisme Dalam Penerapan Sistem Perbankan Syariah", Economica: Jurnal Ekonomi Islam, (Semarang: Fakultas Ekonomi dan Bisnis Islam UIN Walisongo), Vol 5, No 2 (2014).

Solihin Ismail, Corporate Social Responsibility (CSR). Jakarta: Salemba Empat, 2009. 
ISTINBATH : JURAAL HUKUM. VOL. I 5 nO.2. nOV. 2018

Totok Mardikanto, CSR (Corporate Social Responsibility) Tanggung Jawab Sosial Korporasi, Bandung: Afabeta, 2014. 